\title{
Outcomes of Behavioral Intervention for Children with Autism in Mainstream Pre-School Settings
}

\author{
Sigmund Eldevik $\cdot$ Richard P. Hastings $\cdot$ \\ Erik Jahr $\cdot$ J. Carl Hughes
}

Published online: 7 April 2011

(c) The Author(s) 2011. This article is published with open access at Springerlink.com

\begin{abstract}
We evaluated outcomes for 31 children with autism (2-6 years of age at intake) who received behavioral intervention in mainstream pre-school settings and a comparison group of 12 children receiving treatment as usual. After 2 years, children receiving behavioral intervention had higher IQ scores (Hedges $g=1.03$ (95\% $\mathrm{CI}=.34,1.72)$ and adaptive behavior composite scores (Hedges $g=.73(95 \% \mathrm{CI}=.05,1.36)$. Despite probably fewer intervention hours, these group level outcomes were comparable to studies providing more intensive intervention. Individual child data also showed positive results with $19.4 \%$ achieving change at a reliable level for IQ; but a lower percentage than found in recent meta-analysis research. Strengths and weaknesses of the mainstream preschool delivery model are discussed.
\end{abstract}

Keywords Early intensive behavioral intervention . Autism · Mainstream setting · Pre-school - Effectiveness

The benefits of Early Intensive Behavioral Intervention (EIBI) for young children with autism are being increasingly documented. Recent reviews of the literature suggest

S. Eldevik $(\square)$

Akershus University College, P.B. 423, 2001 Lillestrøm,

Norway

e-mail: eldevik@online.no

R. P. Hastings - J. C. Hughes

Bangor University, Bangor, UK

E. Jahr

Akershus University Hospital, Akershus, Norway

S. Eldevik

Senter for Tidlig Intervensjon (STI), Oslo, Norway that the effectiveness of EIBI may be considered "well established" according to commonly used criteria for evidence based practices (Eikeseth 2009; Eldevik et al. 2010; Rogers and Vismara 2008), and meta-analytic methods reveal large and moderate effect sizes for outcome assessed via standardized tests of intelligence and adaptive functioning respectively (Eldevik et al. 2009; Makrygianni and Reed 2010; Reichow and Wolery 2009; Virues-Ortega 2010; Peters-Scheffer et al. 2011). To date, the majority of published studies of EIBI included in systematic reviews have focused on its delivery by specialist teams and often with implementation staff engaged as part of a research evaluation project.

The question of whether EIBI might be delivered successfully in more typical service settings, or on a reasonably large scale, has been relatively neglected. Community effectiveness studies of this kind would correspond to the final phase of validating a psychosocial intervention for autism spectrum disorders as proposed by Smith et al. (2007). According to Smith et al., implementing intervention in a real world setting to see whether similar outcomes can be achieved can be considered the ultimate test of effectiveness.

There are various models described in the literature on how EIBI can be implemented (Handleman and Harris 2001). These range from a full time placement in a center (or an institution), home-based programs directed either through a clinic or the parents themselves, to full time placement in mainstream pre-school with EIBI being implemented at home before or after pre-school and at the weekends. Most of the outcome data published so far have come from home-based programs in some form. Homebased EIBI has been organized through university clinics (Lovaas 1987; Remington et al. 2007), and community based agencies or clinics (Cohen et al. 2006; Howard et al. 
2005; Sallows and Graupner 2005). There are a few examples of evaluations of intervention models delivered outside of the home setting. In Norway, Eikeseth et al. $(2002,2007)$ evaluated EIBI for young children with autism in pre-school settings where supervision was provided through specialist health care services, and in Israel BenItzchak and Zachor (2007) evaluated EIBI provided at an intervention clinic.

In terms of outcomes of EIBI when delivered on a large scale, Perry et al. (2008) recently reported on EIBI delivered throughout a Canadian provincial area. EIBI was provided in a variety of settings (including center-based and integrated child care settings) and the evaluation was focused on the effectiveness of EIBI as it might be typically delivered clinically rather than in a controlled research study. Notably, staff training had to be conducted on a large scale in a limited time and no children were excluded based on co-morbid diagnosis, low cognitive ability, or age. Also, children were referred from a large and diverse socioeconomic group. Ostensibly, any one of these factors could lead to a less favorable outcome. The study reported outcomes for 332 children with autism between 2 and 7 years of age. Like in other outcome studies, there was considerable variation in outcome, but overall the children made statistically and clinically significant improvements in intellectual and adaptive functioning and autism severity.

Initial data on delivery of EIBI in various settings, and even on a large scale and in typical clinical practice, are encouraging. However, there is still a need to investigate the effectiveness of models of service delivery in real world settings. Such settings will vary considerably from country to country (and within countries), and thus a variety of models will need to be evaluated. In the city of Oslo, Norway in the year 2000, an early intervention center (Senter for Tidlig Intervensjon; STI) was established that focused on the provision of an EIBI model for pre-school children with autism. As is the current policy in Norway, all children receiving services through the center were enrolled in their local mainstream pre-schools. Referrals to STI were taken from local pedagogical-psychological services (PPT), of which there were seven in the city, each covering a designated geographical area of the city. However, all referrals had to go through a central city education department office for final approval. The services from STI involved no extra financial costs for the family, the pre-school, or the community. The center's mission was to provide specialist early intervention services directly to the pre-schools, thus supporting the local PPT with some of their most difficult cases.

No financial/staffing resources in addition to those typically given to a pre-school enrolling a child with autism were given. A pre-school enrolling a child with autism typically received one additional full-time staff member, and supervision and training from a special education teacher and/or speech and language therapist employed by the local community for $2-5 \mathrm{~h}$ a week. The aim of the current project was instead to provide a behavioral intervention program using these same professional resources, with some additional supervision input. Instead of the preschool receiving supervision and training from local PPT professionals as would usually be the case, this was provided through the behavioral intervention center (STI). Although no formal modeling of costs was carried out, any additional costs for the city would have been associated with the funding of the supervisory staff employed at the intervention center instead of funding supervisory staff through the local PPT services. The pre-school staff (including the extra professional resources employed locally) were responsible for the day-to-day implementation of the behavioral intervention program while being supervised and trained by STI.

The purpose of the present paper is to describe the key features of the Oslo mainstream pre-school EIBI model and to compare outcome data from children enrolled over a 10 year period with children receiving treatment as usual (TAU), which may be best described as eclectic special education intervention.

\section{Methods}

Service Setting and Participants

All children who received intervention through the center from its inception in January 2000 to February 2011, and who met the following criteria, were included in the present analysis: (a) an independent diagnosis of autism or pervasive developmental disorders-not otherwise specified (PDD-NOS/atypical autism from ICD-10) based on the ADI-R (Lord et al. 1994); (b) between 2 and 6 years of age at intake; (c) a full-scale intelligence test and a measure of adaptive behavior administered at intake and after about 2 years of intervention, and (d) at least $5 \mathrm{~h}$ per week of intervention. A comparison group of children meeting these same criteria, and also attending local mainstream pre-schools, but instead receiving TAU in the same time period was provided through the neighboring Akershus University Hospital.

In total, 43 children met the inclusion criteria, 31 from the EIBI center and 12 who were diagnosed via the hospital clinic and were receiving TAU in their local mainstream pre-school. A more detailed description of the groups is provided in Tables 1 and 2. There were no significant differences between the groups on age at intake, duration of intervention, the distribution of diagnoses, or gender. 
Table 1 Age at intake, intervention hours per week and duration, for each group

\begin{tabular}{|c|c|c|c|c|}
\hline \multirow[t]{2}{*}{ Characteristics } & \multicolumn{2}{|c|}{ EIBI group $(n=31)$} & \multicolumn{2}{|c|}{ Comparison group $(n=12)$} \\
\hline & M & SD (range) & M & SD (range) \\
\hline Age at intake & 42.2 & $9.0(26-70)$ & 46.2 & $12.4(24-67)$ \\
\hline Hours spent on weekly goals & 13.6 & $5.3(6.5-28)$ & $5+$ (unspec.) & - \\
\hline Duration of intervention in months & 25.1 & $6.3(10-34)$ & 24.6 & $10.8(13-49)$ \\
\hline
\end{tabular}

Table 2 Diagnosis, gender and level of intellectual functioning, number ofchilldren and percentage in each group

\begin{tabular}{|c|c|c|c|c|}
\hline \multirow[t]{2}{*}{ Characteristic } & \multicolumn{2}{|c|}{ EIBI group $(n=31)$} & \multicolumn{2}{|c|}{ Comparison group $(n=12)$} \\
\hline & $n$ & Percentage & $n$ & Percentage \\
\hline \multicolumn{5}{|l|}{ Diagnosis } \\
\hline Autism & 25 & 80.6 & 9 & 75.0 \\
\hline PDD-NOS & 5 & 16.1 & 3 & 25.0 \\
\hline Asperger & 1 & 3.2 & 0 & 0 \\
\hline \multicolumn{5}{|l|}{ Gender } \\
\hline Male & 25 & 80.6 & 8 & 66.7 \\
\hline Female & 6 & 19.4 & 4 & 33.3 \\
\hline \multicolumn{5}{|c|}{ Level of intellectual disability } \\
\hline No ID & 4 & 12.9 & 2 & 16.7 \\
\hline Mild ID & 10 & 32.3 & 4 & 33.3 \\
\hline Moderate ID & 12 & 38.7 & 5 & 41.7 \\
\hline Severe ID & 5 & 16.1 & 1 & 8.3 \\
\hline Profound & 0 & .0 & 0 & .0 \\
\hline
\end{tabular}

Furthermore, the proportions of children with severe, moderate, mild, and no intellectual disability where similar in the two groups at intake. Overall, the average IQ and adaptive behavior composite scores in both of the groups were slightly lower than the general population of children with autism spectrum disorders (Volkmar and Klin 2005).

\section{Pre-School Setting}

Participants that received EIBI through the center were referred from pedagogical-psychological services (PPT) through the educational authorities in the city. The referral process would normally start with either the parents or staff at the pre-school raising concerns about the child, and referring it to the local PPT for an assessment by a consultant (a psychologist or special education teacher). The consultant would then write a proposed statement of the child's need, and how they could be met. The PPT staff were not trained in diagnosing children, so if there was suspicion of a diagnosis within the autism spectrum (or any other diagnosis) the child was referred on to specialist services within the health care system. By law, special education provision should not be based on a particular diagnosis but rather on the child's needs. Thus, the proposed statement did not have to wait for a formal diagnosis to be made but was sent to a central city education department office for final approval. Based on the child's needs and the wording in the statement the child was referred on from here to units that provide intervention and/ or support for the child. Several options are available depending on the child's needs. Some children can get their intervention supervised by the local PPT, some are referred to the health care system, and some are referred to STI or to another service provider in the city. All of these services base their support on training and supervision of locally employed professionals and pre-school staff.

All children in the EIBI and TAU groups attended their local mainstream pre-school. The pre-schools were in Oslo and Akershus County (total population ca 1.1 million). In most cases, a pre-school would have enrolled only one child with autism. As required by Norwegian regulations, mainstream pre-school units were staffed on 1:3 staff to child ratio for children under the age of 3 years, and a 1:6 staff to child ratio for children between 3 and 6 years of age (children started school proper at 6 years of age). In their final year of pre-school, special "clubs" are arranged to prepare the children for school. Typically, a pre-school unit would either consist of nine children below the age of three with three staff, or 18 children between the age of three and six with three staff. When the unit enrolled a 
child with autism, resources were normally received for one more full-time staff member making it possible to cover this child 1:1 without taking resources away from the other children in the unit. This extra resource was granted independent of any particular intervention (and of the current study). All units had a separate room available where 1:1 intervention could be done without disturbance from the rest of the unit. Pre-schools were typically open weekdays from 7:00 am to 5:00 pm, and children in the present study were typically at the pre-school for at least $20 \mathrm{~h}$ every week (typically, a minimum of $4 \mathrm{~h}$ per day).

Some of the $1: 1 \mathrm{~h}$ in the unit merely focused on practical help for getting dressed or undressed, eating, toileting, and going outside on the playground, without the use of systematic teaching methods. For the purposes of this study, only the hours spent implementing teaching methods towards specified weekly targets (whether inside or outside of the teaching room) were counted as intervention hours, while hours of general practical assistance only were not counted. Practical assistance hours were generally similar for all children in the pre-school settings.

\section{Interventions}

\section{EIBI Group}

The county of Oslo, Norway in 2000 started a center that was to provide EIBI for children with autism. The center was to do this by offering supervision and training of existing personnel in the preschools. The center employed one psychologist and four supervisors. The psychologist (first author) was a Board Certified Behavior Analyst with approximately 15 years of experience implementing EIBI programs and served as a consultant for the supervisors. The supervisors had bachelors degrees (in habilitation of individuals with various handicaps) covering the basics of applied behavior analysis and between 2 and 10 years of training and experience with EIBI programs.

For organizing the intervention, we recommended that 2-3 staff members from the unit formed an intervention team responsible for the day-to-day implementation of the intervention, rather than having just the extra staff member cover the child with autism. A rota was made so that all team members would work with the child during the week. This was also done so that the child would get used to interacting with a number of different adults and so as not to make the program dependent on just one person. One of the team members was given responsibilities for scheduling and monitoring intervention hours, preparing the weekly team meetings, updating the program records, and finding the instructional materials needed for the various programs.

The center was responsible for training and supervision of all staff involved in the intervention. The model used for staff training and supervision was similar to that described as clinic-supervised intervention by Smith et al. (2001) and Eikeseth et al. (2002). Staff training started with a threeday workshop and continued throughout the duration of the intervention with weekly (or eventually in some cases biweekly) consultations lasting $1-4 \mathrm{~h}$. In addition, weekly 2-h team meetings were held for each child. The child, primary caregiver(s), and staff attended both the workshops and the team meetings, and all were trained using an apprenticeship model. The supervisor first explained and demonstrated how to do a program, and then the staff took turns doing the program with the child, while being coached by the supervisor and the other team members. At team meetings, the child's program and/or intervention procedures were reviewed and modified based on the child's progress during the preceding week. The program was comprehensive and balanced covering all important areas of the child's life. Each week the child would normally be engaged in 10-20 teaching programs. Parental participation was encouraged to ensure generalization and maintenance of skills to the home and other community settings.

Depending on the needs of the individual child, parts of the intervention were provided outside of the separate teaching room, targeting specific weekly goals (e.g., conducting incidental teaching for expressing wants and needs, providing instruction on self-help skills such as putting on shoes, teaching peer interaction skills, or implementing behavior management plans). The supervisors had a caseload of 4-8 children. They met weekly (or more often if required) with the psychologist to discuss programming or any particular problems arising with individual children. The psychologist would also oversee individual programs by attending team-meetings at least once a semester.

The intervention was based on several widely used EIBI manuals (Leaf and McEachin 1999; Lovaas 1981, 2003; Maurice et al. 1996; Sundberg and Partington 1998). In short, the intervention began with establishing basic tasks, such as expressing wants and needs, responding to simple requests made by an adult, imitation of gross motor behaviors, matching of objects or pictures, and teaching of simple toy play such as completion of puzzles or putting shapes in a shape sorter. When these tasks were mastered, the intervention moved on to more complex skills such as imitation of fine motor and oral motor behaviors, imitation of sounds and words, and recognizing objects and actions upon request. After the child had acquired vocal imitation of words and basic receptive language, the child was taught to use the words functionally, for example by naming objects and actions. Next, more abstract concepts such as color, size, adjectives, and prepositions were targeted. Subsequent intervention goals included discriminating Wh-questions, conversing, and making friends with peers. 
From the start, the intervention also targeted other play and social skills, progressing from functional toy play and parallel play to symbolic play and cooperative play.

All procedures were based on documented operant conditioning techniques such as differential reinforcement, shaping, chaining, task analysis, and prompt and prompt fading. In the early stages of intervention, most teaching took place in a 1:1 discrete trial format. Later, the focus gradually shifted to include small group settings with typically developing children to help generalize skills and adjust to the routines of the pre-school unit. The ultimate goal of the intervention was to improve the ability of the children to learn in natural settings as might be expected of their typically developing peers.

\section{Comparison (Treatment as Usual) Group}

For children in this group, elements from various types of interventions were combined in an attempt to best meet the child's educational needs. The intervention typically included a mix of the following intervention types: alternative communication, applied behavior analysis (ABA), total communication, sensory motor therapies, programs based on the principles from TEACCH, as well as other methods that were incorporated based on the personal experience of the particular special education teacher and staff. The organization of supervision and staff training for the comparison group was in some ways similar to that of the EIBI group. A special education teacher from the local educational authorities would do one or two weekly consultations totaling about $2-5 \mathrm{~h}$ a week. The agency to be responsible for supervision and training was determined in the interdisciplinary educational planning process for each child. Within each agency a particular person was assigned on the basis of capacity and/or geographical location. As in the EIBI group, between one and three therapists were recruited from the pre-school staff to do the daily work with the child.

The intervention components typically found in the comparison group can be summarized as follows. Any ABA intervention would typically include working on a small number of selected programs from ABA treatment manuals such as matching, imitation, or toilet training. Data on the number of hours of this intervention in the TAU group were not available, but the intervention was qualitatively different because of the focus on small numbers of selected programs rather than a comprehensive model. Alternative communication would typically include working towards a symbol or sign based communication system. Symbols were typically line drawings, Bliss symbols or photographs taken of objects, persons, or activities from the child daily life. Signs would typically be hand signs for expressing needs such as "Food," "Water," or
"Toilet". Sensory integration would typically involve daily activity sessions of 15-20 min of going on a swing, rocking and stretching while listening to music, or getting a massage. Total Communication elements would include strategies for the complementary use of signs, symbols and speech to enhance verbal comprehension, improve expressive language and develop a form of literacy. Intervention would focus on broadening the medium of communication to include signs, symbols, pictures, photographs and objects, as well as speech. It might also involve the use of drama, mime, or other forms of visual communication. Elements taken from TEACCH would typically involve making length and content of sessions predictable by using picture schedules and baskets to separate the tasks and assigning areas for specific activities. The intervention elements that were reported to be based on the teacher's clinical experience would typically involve the use of worksheets, learning through educational software on a computer, and training social skills through listening to stories and looking at picture sequences.

Unfortunately, because this was an evaluation of typical clinical practice we were not successful in measuring accurately the total time spent on intervention in the comparison group, or measuring the proportion of time spent on the various intervention approaches that were implemented and are described briefly above. Typically, sessions were conducted throughout the day taking advantage of opportunities that arose in daily life when the child was motivated. Also, intervention approaches were often combined in the same session, so that when applying principles derived from TEACCH, such as structuring daily activities with baskets, the staff simultaneously used techniques derived from $\mathrm{ABA}$, such as reinforcement and prompting, and principles from total communication, such as combining visual and verbal modalities to promote spoken language.

\section{Outcome Measures}

We employed measures of full scale intellectual functioning and adaptive behavior that are widely used and recommended for assessing children with autism (Klin et al. 2005).

\section{Intellectual Functioning}

The Bayley Scales of Infant Development (BSID), second or third edition (Bayley 1993, 2006) was used for the youngest children or children that scored below the basal on intelligence tests standardized for their chronological age. The BSID is a measure of mental development for children up to 42 months. It will yield a mental developmental index (MDI), which was considered broadly 
equivalent to an IQ score. If the child scored below the norms on this test or was too old for the norms, we computed a ratio IQ score by dividing the obtained mental age with chronological age and multiplying by 100 . For the older children we used the Stanford-Binet Intelligence Scale: Fourth or Fifth Edition (Thorndike et al. 1986; Roid 2003), or the Norwegian version of the Wechsler Preschool and Primary Scale Intelligence-Revised (Wechsler 1989).

\section{Adaptive Behavior}

The Vineland Adaptive Behavior Scales (VABS I or II; Sparrow et al. 1984, 2005) were used for measuring adaptive behavior. The VABS yields standard scores on four domains; communication, daily living, socialization, and for children under 6 years old, motor skills. Based on these scores the VABS also yields a standardized adaptive behavior composite (ABC).

Just under $60 \%$ of the assessments for the children in the EIBI group were carried out by professionals blind to the purposes of the present study (67\% at intake, and $48 \%$ after 2 years). The remainder of the assessments were conducted by the first author. Six of these administrations were performed both by an independent professional and by the first author within 3 months of each other. In these instances, a conservative measure of improvement was obtained by using the higher score at intake and the lower score in the later assessments. Agreement on the total scores for assessments was within \pm 5 standard points in all of these "overlap" cases. As an added precaution we analyzed outcome data to see if there were any differences in the reported gains between the children that were tested by somebody independent of the study and the children who were tested by the first author (either at intake, after 2 years, or both). Ten children in the EIBI had all assessments completed by an independent professional and 21 children were tested by the first author at one or more points. Average gains were higher for the 10 children tested by an independent assessor both on IQ (22.1 and 11.7 point gains respectively) and $\mathrm{ABC}$ scores (6.6 and 5.7 point gains respectively) although these differences were not statistically significant. Thus, although this clearly cannot be ruled out, we could find no evidence of a positive bias introduced by the proportion of non-blind assessments. All children in the comparison (TAU) group were assessed by psychologists at the paediatric habilitation unit blind to purposes of this study.

\section{Data Analysis}

The first level of analysis was to analyze group differences using ANCOVA models. Because the children were not randomly assigned to groups or actively matched, the intake score for the specific outcome measure along with age at intake were entered as covariates in each analysis. Age in months was used as a covariate because, although not statistically significant, there was a 4 month age difference in the groups and age is also commonly held to be related to outcome. ANCOVAs were conducted for IQ and adaptive behavior scores, including all sub domains (except for motor skills). Based on the mean differences in outcome between the groups, standardized effect size measures were calculated for IQ and ABC scores. In an attempt to correct for the small samples sizes, the Hedges' $g$ effect size was employed.

The second level of analysis was to examine meaningful change at the level of the individual children, following Remington et al. (2007) who used a reliable change analysis (Jacobson and Truax 1991) for the children in their outcome research. An analysis of reliable change establishes with $95 \%$ certainty that observed changes at an individual level are meaningful and not accounted for by measurement error and sample variance. The amount of change required for IQ and $\mathrm{ABC}$ scores to be considered as reliable change was established from a benchmark analysis of almost 300 individual children who received EIBI across 16 separate evaluation studies (Eldevik et al. 2010). These authors established, using the formulae from Jacobson and Truax (1991), that change in IQ over approximately 2 years would need to be $27+$ points to be considered reliable $(21+$ points for adaptive behavior composite standard scores-ABC).

The final exploratory analysis focused on correlates of change. Pearson correlations (2-tailed, and using point biserial correlations where a correlate was dichotomous) were computed between IQ and $\mathrm{ABC}$ change with the following variables: age at intake, IQ at intake, $\mathrm{ABC}$ scores at intake, child gender, diagnosis (autism, vs. PDD-NOS and Asperger syndrome), and intensity of intervention.

\section{Results}

The ANCOVA models we used to analyze outcomes showed that the EIBI group made significantly larger gains on intelligence, $F(1,39)=9.53, p=.004$, and adaptive behavior composite scores, $F(1,39)=4.74, p=.036)$. The same pattern in favor of EIBI was also seen on two of three sub domains on the VABS: communication, $F(1$, $38)=4.82, p=.034$, and socialization, $F(1,38)=7.79$, $p=.008$. The difference on the daily living skills sub domain was not statistically significant $F(1,38)=2.91$, $p=.094$, although still in favor of the EIBI group. The mean scores, standard deviations and ranges, for each group at intake and after 2 years of intervention are displayed in Table 3. The Hedges' $g$ standardized mean 
Table 3 Unadjusted means and SDs of scores at intake and after ca two years of intervention by group

\begin{tabular}{|c|c|c|c|c|c|c|c|c|c|c|c|c|}
\hline \multirow[t]{3}{*}{ Measures } & \multicolumn{6}{|c|}{ EIBI group $(n=31)$} & \multicolumn{6}{|c|}{ Comparison group $(n=12)$} \\
\hline & \multicolumn{2}{|c|}{ Intake } & \multicolumn{2}{|c|}{ After 2 years } & \multicolumn{2}{|c|}{ Change } & \multicolumn{2}{|c|}{ Intake } & \multicolumn{2}{|c|}{ After 2 years } & \multicolumn{2}{|c|}{ Change } \\
\hline & $M$ & SD (range) & $M$ & SD (range) & $M$ & SD & $M$ & SD (range) & $M$ & SD (range) & $M$ & SD \\
\hline Intellectual functioning** & 51.6 & $16.9(24-94)$ & 66.6 & $24.8(23-110)$ & 15.1 & 14.9 & 51.7 & 18.1(30-89) & 52.2 & $22.0(23-86)$ & .5 & 9.5 \\
\hline \multicolumn{13}{|l|}{$\begin{array}{l}\text { Vineland adaptive behavior } \\
\text { scales }\end{array}$} \\
\hline Adaptive behavior composite* & 62.5 & $8.2(46-77)$ & 68.4 & $12.6(46-97)$ & 5.9 & 9.7 & 58.9 & $7.8(50-73)$ & 59.6 & $11.8(47-83)$ & .7 & 10.3 \\
\hline Communication* & 61.9 & $10.2(48-89)$ & 70.5 & $16.9(42-114)$ & 8.6 & 14.6 & 60.0 & $9.6(49-81)$ & 60.0 & $14.5(42-84)$ & .0 & 12.6 \\
\hline Daily living & 69.9 & $10.8(48-89)$ & 72.0 & $12.9(47-93)$ & 2.1 & 11.5 & 64.8 & $10.6(54-91) 63.2$ & 63.2 & $14.2(48-95)$ & -1.6 & 12.5 \\
\hline Socialization** & 63.3 & 9.8(49-97) & 69.1 & $12.0(49-90)$ & 5.8 & 10.9 & 63.1 & $8.9(53-82)$ & 60.8 & $8.6(41-80)$ & -2.3 & 8.8 \\
\hline
\end{tabular}

$* p<.05 ; * * p<.01$ on main effects

difference effect size was 1.03 (95\% confidence interval $[\mathrm{CI}]=.34,1.72)$ for changes in IQ and $.73(95 \% \mathrm{CI}=.05$, 1.36) for changes in ABC scores.

Data from the individual children after 2 years of intervention are displayed in Fig. 1. Each bar on the graph represents an individual child's change in test score. These have been sorted left to right from highest negative to highest positive change. The solid line on the y-axis shows the criterion for reliable change (from Eldevik et al. 2010) and the dotted line shows the mean gain for the group. In the EIBI group, six of the 31 children (19.4\%) met criteria for reliable change in IQ $(27+$ points $)$, and two of the 31 children $(6.5 \%)$ met the criterion for reliable change in ABC $(21+$ points $)$. In the comparison group, no children met either criterion.

Three variables were significantly associated with outcome in the EIBI group. Age at intake correlated positively with gains in ABC scores, and other diagnosis (PDD-NOS or Asperger syndrome, rather than autism) was associated with larger gains in $\mathrm{ABC}$ scores, and larger gains in the communication and daily living skills sub domain. Furthermore, IQ at intake correlated positively with change in the socialization sub domain of the VABS (see Table 4).

\section{Discussion}

Children receiving EIBI under the current mainstream preschool model made statistically significant gains in IQ and adaptive behavior composite scores after 2 years of intervention, when compared to a group receiving special education "treatment as usual". The differences where also statistically significant for the communication and socialization sub domains on the VABS, but not the daily living skills sub domain. Effect sizes for the present study were similar to effect sizes for EIBI recently reported in metaanalytic reviews. For example, an overall meta-analytic effect size for IQ change was 1.1, and for change in VABS
ABC .67 in Eldevik et al. (2009), compared to 1.03 and .73 in the present study.

With an average of 13.6 weekly hours of intervention, the present study should probably also be considered lowintensity, although children were provided with almost $3 \mathrm{~h}$ per day of systematic intervention and 1:1 support for the rest of the day. If we compare outcomes from the present study with studies that have provided the recommended ca $30 \mathrm{~h}$ or more of weekly intervention, the outcomes do not appear to be as strong. In the meta-analysis published by Virues-Ortega (2010), many of the higher-intensity studies had larger effect size estimates for changes in IQ (e.g., Eikeseth et al. 2002, Effect size [ES] = 1.34; Sallows and Graupner 2005, ES = 1.97), and for changes in ABC (e.g., Eikeseth et al. 2002, ES = 1.96; Sallows and Graupner 2005, ES = 1.67). Several recent reviews have indeed reported a positive relationship between intervention hours and outcome (Eldevik et al. 2010; Virues-Ortega 2010).

Despite the potential association between intensity and outcomes, there is no accepted standard for measuring intensity of behavioral intervention and the validity of our measurement needs to be questioned. In particular, it may be that we have counted intervention hours in a more stringent way than other researchers have done. For example, since the staff had considerable training in the EIBI techniques it is highly likely that they provided some sort of intervention (e.g., incidental teaching, systematic fading of prompt) in addition to the intervention hours actually counted.

Considering the relatively low intensity of intervention, the outcome data presented here seem encouraging particularly in terms of meaningful gains in IQ scores for individual children. The percentages of children meeting reliable change criteria after 2 years $(19.4 \%$ for IQ and $6.5 \%$ for $\mathrm{ABC}$ ) are somewhat lower than the data reported by Eldevik et al. (2010), in particular for gains in ABC. Relatively low gains in $\mathrm{ABC}$ scores have also been reported in other low-intensity intervention studies 

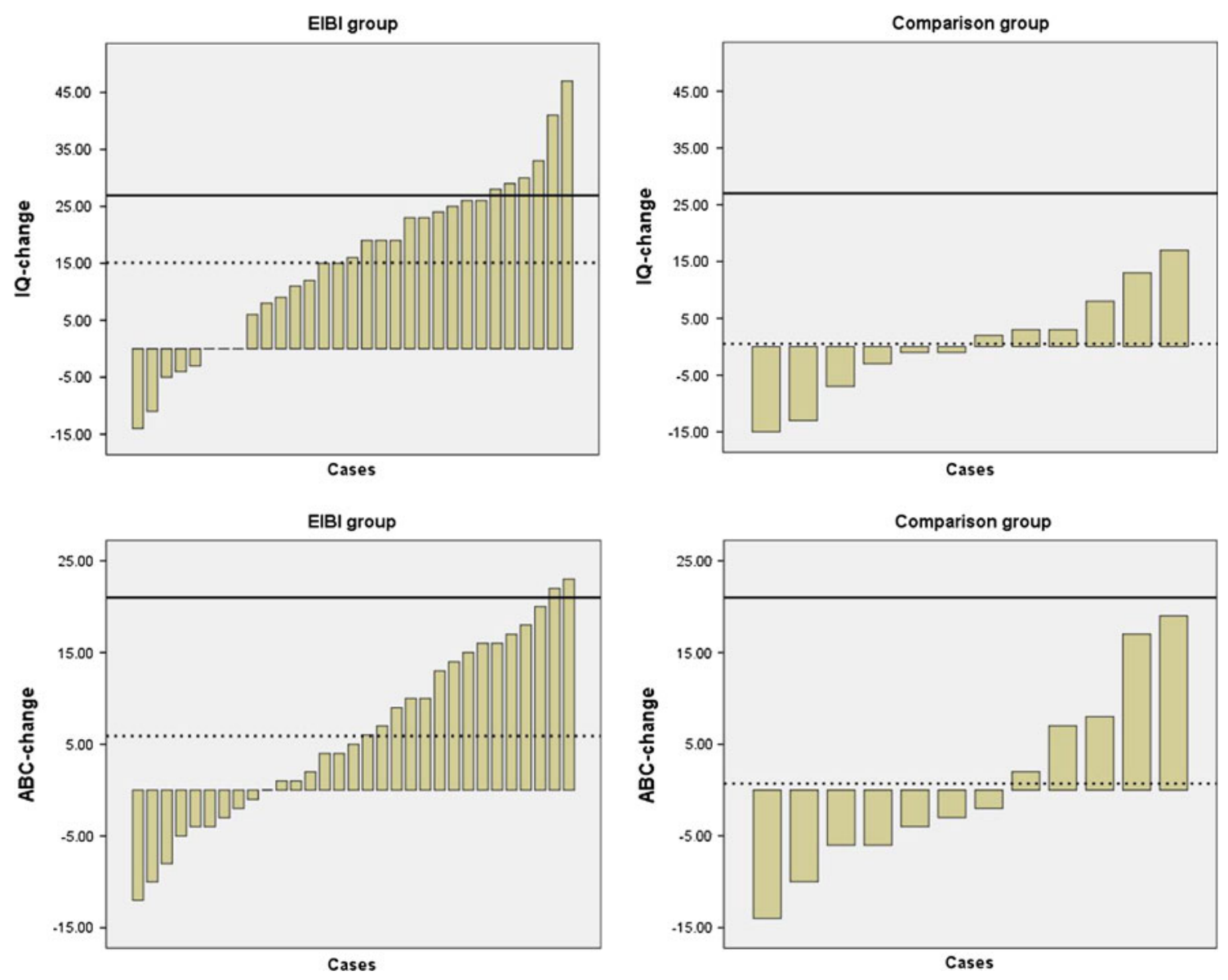

Fig. 1 Bars indicate changes in IQ and ABC scores for individual children in each group following 2 years of intervention. Results are sorted from highest negative to highest positive. The solid lines

represent the Reliable Change benchmarks, 27 for IQ and 21 for ABC (Eldevik et al. 2010), the dotted lines represent the mean change in each group

Table 4 Correlations between age at intake, scores at intake, weekly intervention hours, gender, diagnosis (autism vs. other) and outcome variables

\begin{tabular}{lllllll}
\hline $\begin{array}{l}\text { Outcome } \\
\text { measures }\end{array}$ & \multicolumn{6}{l}{ Intake variables } \\
\cline { 2 - 7 } & Age & IQ & ABC & Gender & Diagnosis & $\begin{array}{l}\text { Weekly } \\
\text { hours }\end{array}$ \\
\hline IQ & .033 & .214 & .221 & -.252 & .204 & .148 \\
ABC & $.387 *$ & .342 & -.027 & .225 & $.506^{* *}$ & .207 \\
Communication & .242 & .293 & .157 & .341 & $.422^{*}$ & .216 \\
$\begin{array}{l}\text { Daily living } \\
\text { skills }\end{array}$ & .238 & .312 & -.120 & .157 & $.549^{* *}$ & -.046 \\
Socialisation & .171 & $.390^{*}$ & .028 & -.091 & .183 & .285 \\
\hline
\end{tabular}

$* p<.05 ; * * p<.01$

(Eldevik et al. 2006). Indeed, gains in ABC appear to be inconsistent across intervention studies (Virues-Ortega 2010). Some researchers have reported small standardized gains in the intervention groups, but still a statistically significant difference when compared to control groups because adaptive behavior standard scores may reduce over

time in treatment as usual comparison groups (e.g., Dawson et al. 2010; Rogers \& Dawson 2010).

In addition, we found that weekly hours of intervention did not correlate significantly with outcome. The reason for this may be that there was little variability in intensity in the present study. Furthermore, we failed to find a correlation between IQ at intake and IQ gain. Some individual studies have reported such a relationship (e.g., Harris and Handleman 2000), but meta-analytic reviewers have also failed to find such a correlation.

There was, however, tentative evidence of an association between autism diagnosis (with those with PDD-NOS performing better) and gain in $\mathrm{ABC}$ scores and the VABS sub-domain of daily living skills. This pattern has been found in another study (Smith et al. 2000). The number of PDD-NOS cases in the present evaluation is small (as it was in the Smith et al. study) and thus this result may not be robust. Examination of differential outcomes for a variety of Pervasive Developmental Disorders remains a question for future research. 
There are limitations in the research design of the present study. Children were not randomly assigned to groups and instead this was based on geographical location. In addition to the possible bias relating to group assignment, there is a potential for further bias in the actual referral process to the regional intervention centre. Both at the local PPT and at the City's central office any number of considerations could affect whether or not a particular child was referred to STI. Although there were no formal guidelines in terms of the child's level of functioning, age, what pre-school the child attended, and so on, it may well be that some children were referred on the basis of these (or some other unknown) variable. Unfortunately, we do not have data on the factors affecting referral decisions, but children from some parts of the City were probably over-represented. This could be because other service providers were better established in parts of the city, or the pattern of referral may reflect the professional preferences of the local PPT.

A further limitation of the present study was that only IQ and adaptive behavior outcome data were available. Behavioral intervention has also been associated with positive effects on language and cardinal features of autism (e.g., joint attention) in previous research (e.g., Remington et al. 2007). Thus, future evaluations of this mainstream pre-school model and other service delivery models should endeavor to examine a wider range of outcomes.

Like in the large-scale study from Canada (Perry et al. 2008), no children were excluded based on low IQ scores or socio-demographic variables. Sixteen of the 31 children in the EIBI group were from ethnic groups in the minority in Norway, and to some of the parents the diagnosis of autism and the association with special education provision was unknown or associated with shame. For this, and other reasons, it was sometimes difficult to achieve parental involvement. Future research may need to focus on how parental involvement can best be maximized as a support to the generalization and maintenance of children's skills.

In addition to the formal outcome data, it is important to review the strengths and weaknesses of this mainstream preschool model for the delivery of behavioral intervention to children with autism. Strengths include that trained staff are with the children for the entire day, and inclusion in mainstream settings provided opportunities for interaction with peers, who may also serve as role models (cf. Grindle et al. 2009). The weaknesses of this model are also notable: it was in most cases difficult to reach the typically recommended weekly intervention hours due to competing contingencies on the staff in the mainstream pre-school. Also, there was often a 3-9 month period before the intervention program was up and properly running. The staff and pre-school management were in most cases unfamiliar with (and in some cases opposed to) EIBI. Behavioral intervention is different in many ways to the generic education provided in mainstream pre-schools. The close supervision and monitoring of staff performance and the child's learning, the intensity of intervention, and the structure of teaching (in particular, the discrete trials format) may be at odds with the educational approaches pre-school staff were used to. In most cases, such skepticism was overcome, but in two cases (excluded from the present analysis) these problems led to the children receiving so few weekly intervention hours that the programs were discontinued.

The outcome data, and the clinical experience of involvement with this mainstream pre-school model for 10 years, suggest that it holds considerable promise for the delivery of behavioral intervention to young children with autism. However, the model has some inherent problems. It was difficult to get the recommended numbers of weekly intervention hours, due to competing contingencies in the pre-school. The model could be improved further if the extra locally employed professionals provided to the pre-schools when they enrolled a child with autism were instead employed directly through the intervention center. If this was the case, better continuity could be achieved and these staff would build up experience with EIBI, which would in turn make it possible to get the programs up and running more quickly. Furthermore, the intervention center would not have to use as many resources in training new staff.

In conclusion, the outcomes from the delivery of an EIBIbased model to pre-school children in typical mainstream nursery settings led to more positive outcomes than a Treatment as Usual special education nursery model for children with autism. In terms of effect sizes, the results were similar to those from recent meta-analyses. In addition, almost $20 \%$ of the individual children In the EIBI group achieved substantial and meaningful changes in IQ whereas no child in the TAU group changed to this extent. These data suggest that an EIBI-based model can be effective when delivered in community settings (cf. Smith et al. 2007).

Acknowledgments This paper was submitted as part of the first author's Ph.D. thesis at Bangor University. We would like to thank the staff employed at STI: Hege Aarlie, Hege Tryggestad, Tone Åker, Astri Valmo, Kim Liland, Alfred Steinvik, Are Karlsen, Per Holth, Cathrine Olson, Silje Haugland, Elisabeth Ulvestad, Rannveig Nesset and Birgitte Kaldhussæter.

Open Access This article is distributed under the terms of the Creative Commons Attribution Noncommercial License which permits any noncommercial use, distribution, and reproduction in any medium, provided the original author(s) and source are credited.

\section{References}

Bayley, N. (1993). Bayley scales of infant development (2nd ed.). San Antonio, TX: The Psychological Cooperation.

Bayley, N. (2006). Bayley scales of infant and Toddler development (3rd ed.). San Antonio, TX: Harcourt Assessment. 
Ben-Itzchak, E., \& Zachor, D. A. (2007). The effects of intellectual functioning and autism severity on outcome of early behavioral intervention for children with autism. Research in Developmental Disabilities, 28, 287-303.

Cohen, H., Amerine-Dickens, M., \& Smith, T. (2006). Early intensive behavioral treatment: Replication of the UCLA model in a community setting. Developmental and Behavioral Pediatrics, $27,145-155$.

Dawson, G., Rogers, S., Munson, J., Smith, M., Winter, J., Greenson, J., et al. (2010). Randomized, controlled trial of an intervention for toddlers with autism: The early start Denver model. Pediatrics, $125,17-23$.

Eikeseth, S. (2009). Outcome of comprehensive psycho-educational interventions for young children with autism. Research in Developmental Disabilities, 30, 158-178.

Eikeseth, S., Smith, T., Jahr, E., \& Eldevik, S. (2002). Intensive behavioral treatment at school for 4- to 7-year-old children with autism: A 1-year comparison controlled study. Behavior Modification, 26, 49-68.

Eikeseth, S., Smith, T., Jahr, E., \& Eldevik, S. (2007). Outcome for children with autism who began intensive behavioral treatment between ages 4 and 7: A comparison controlled study. Behavior Modification, 31, 264-278.

Eldevik, S., Eikeseth, S., Jahr, E., \& Smith, T. (2006). Effects of lowintensity behavioral treatment for children with autism and mental retardation. Journal of Autism and Developmental Disorders, 36, 211-224.

Eldevik, S., Hastings, R. P., Hughes, J. C., Jahr, E., Eikeseth, S., \& Cross, S. (2009). Meta-analysis of early intensive behavioral intervention for children with autism. Journal of Clinical Child and Adolescent Psychology, 38, 439-450.

Eldevik, S., Hastings, R. P., Hughes, J. C., Jahr, E., Eikeseth, S., \& Cross, S. (2010). Using participant data to extend the evidence base for intensive behavioral intervention for children with autism. American Journal on Intellectual and Developmental Disabilities, 115, 381-405.

Grindle, C., Hastings, R. P., Saville, M., Hughes, J. C., Kovshoff, H., \& Huxley, K. (2009). Integrating evidence-based behavioural teaching methods into education for children with autism. Educational and Child Psychology, 26, 65-81.

Handleman, J. S., \& Harris, S. L. (2001). Preschool education programs for children with autism (2nd ed.). Austin, Texas: PRO-ED.

Harris, S. L., \& Handleman, J. S. (2000). Age and IQ at intake as predictors of placement for young children with autism: A fourto six-year follow-up. Journal of Autism and Developmental Disorders, 30, 137-142.

Howard, J. S., Sparkman, C. R., Cohen, H. G., Green, G., \& Stanislaw, H. (2005). A comparison of intensive behavior analytic and eclectic treatments for young children with autism. Research in Developmental Disabilities, 26, 359-383.

Jacobson, N. S., \& Truax, P. (1991). Clinical significance: A statistical approach to defining meaningful change in psychotherapy research. Journal of Consulting and Clinical Psychology, 59, 12-19.

Klin, A., Saulnier, C., Tsatsanis, K., \& Volkmar, F. R. (2005). Clinical evaluation in autism spectrum disorders: Psychological assessment within a transdisciplinary framework. Hoboken, NJ: Wiley.

Leaf, R., \& McEachin, J. (1999). A work in progress. New York: DRL Books.

Lord, C., Rutter, M., \& Le Couteur, A. (1994). Autism diagnostic interview-revised: A revised version of a diagnostic interview for caregivers of individuals with possible pervasive developmental disorders. Journal of Autism and Developmental Disorders, 24, $659-685$.
Lovaas, O. I. (1981). Teaching developmentally disabled children: The me book/by O. Ivar Lovaas, with Andrea Ackerman. [et al.] and with contributions by Edward G. Carr and Crighton Newsom. Baltimore: University Park Press.

Lovaas, O. I. (1987). Behavioral treatment and normal educational and intellectual functioning in young autistic children. Journal of Consulting and Clinical Psychology, 55, 3-9.

Lovaas, O. I. (2003). Teaching individuals with developmental delays: Basic intervention techniques. Austin, TX: Pro-Ed.

Makrygianni, M. K., \& Reed, P. (2010). A meta-analytic review of the effectiveness of behavioural early intervention programs for children with autistic spectrum disorders. Research in Autism Spectrum Disorders, 4, 577-593.

Maurice, C., Green, G., \& Luce, S. C. (Eds.). (1996). Behavioral intervention for young children with autism: A manual for parents and professionals. Austin, TX: Pro-Ed, Inc.

Perry, A., Cummings, A., Geier, J. D., Freeman, N. L., Hughes, S., LaRose, L., Managhan, T., Reitzel, J.-A., \& Williams, J. (2008). Effectiveness of intensive behavioral intervention in a large, community-based program. Research in Autism Spectrum Disorders, 2, 621-642.

Peters-Scheffer, N., Didden, R., Korzilius, H., \& Sturmey, P. (2011). A meta-analytic study on the effectiveness of comprehensive ABAbased early intervention programs for children with autism spectrum disorders. Research in Autism Spectrum Disorders, 5, 60-69.

Reichow, B., \& Wolery, M. (2009). Comprehensive synthesis of early intensive behavioral interventions for young children with autism based on the UCLA young autism project model. Journal of Autism and Developmental Disorders, 39, 23-41.

Remington, B., Hastings, R. P., Kovshoff, H., Espinosa, F., Jahr, E., Brown, T., et al. (2007). Early intensive behavioral intervention: Outcomes for children with autism and their parents after two years. American Journal on Mental Retardation, 112, 418-438.

Rogers, S. J., \& Dawson, G. (2010). Early start Denver model for young children with autism: Promoting language, learning, and engagement. New York: Guilford.

Rogers, S. J., \& Vismara, L. A. (2008). Evidence-based comprehensive treatments for early autism. Journal of Clinical Child and Adolescent Psychology, 37, 8-38.

Roid, G. H. (2003). Stanford-Binet intelligence scales, fifth edition, technical manual. Itasca, IL: Riverside Publishing.

Sallows, G. O., \& Graupner, T. D. (2005). Intensive behavioral treatment for children with autism: Four-year outcome and predictors. American Journal on Mental Retardation, 110, $417-438$.

Smith, T., Donahoe, P. A., \& Davis, B. J. (2001). The UCLA young autism project. In J. S. Handleman \& S. L. Harris (Eds.), Preschool education programs for children with autism (2nd ed.). Austin, Texas: PEO-ED.

Smith, T., Groen, A. D., \& Wynn, J. W. (2000). Randomized trial of intensive early intervention for children with pervasive developmental disorder. American Journal on Mental Retardation, 105, 269-285.

Smith, T., Scahill, L., Dawson, G., Guthrie, D., Lord, C., Odom, S., et al. (2007). Designing research studies on psychosocial interventions in autism. Journal of Autism and Developmental Disorders, 37, 354-366.

Sparrow, S. S., Balla, D. A., \& Cicchetti, D. V. (1984). Vineland adaptive behavior scales. Minnesota: American Guidance Service.

Sparrow, S. S., Cicchetti, D. V., \& Balla, D. A. (2005). Vineland adaptive behavior scales (2nd ed.). Circle Pines Minnesota: AGS Publishing.

Sundberg, M. L., \& Partington, J. W. (1998). Teaching language to children with autism or other developmental disabilities. Danville, CA: Behavior Analysts, Inc. 
Thorndike, R. L., Hagen, E. R., \& Sattler, J. M. (1986). The StanfordBinet intelligence scale (4th ed.). Chicago: Riverside.

Virues-Ortega, J. (2010). Applied behavior analytic intervention for autism in early childhood: Meta-analysis, meta-regression and dose-response meta-analysis of multiple outcomes. Clinical Psychology Review, 30, 387-399.

Volkmar, F. R., \& Klin, A. (2005). Issues in the classification of autism and related conditions. In F. R. Volkmar, R. Paul, A.
Klin, \& D. Cohen (Eds.), Handbook of autism and pervasive developmental disorders, Vol. 1: Diagnosis, development, neurobiology, and behavior (3rd ed., pp. 5-41). Hoboken, NJ: Wiley.

Wechsler, D. (1989). Wechsler preschool and primary scale of intelligence-revised. San Antonio, TX: Psychological Corporation. 